\title{
Osteopathic Manipulative Treatment Considerations in Tension-Type Headache
}

Elaine Lee, OMS IV; Sean Moloney, DO; Joel Talsma, MS; Stacey Pierce-Talsma, DO

From the Touro University College of Osteopathic Medicine-CA in Vallejo.

Financial Disclosures:

None reported.

Support: This video was produced by the Touro University College of Osteopathic Medicine-CA. Address correspondence to Sean Moloney, DO, 1310 Club Dr, Mare Island, Vallejo, CA 94592-1187.

Email: sean.moloney@tu.edu

Video link: https://drive.google. com/open?id=1 NDhqWxG2 hsqRliavpaTIq3ih2UHoy_DA

Submitted June 6, 2019;

accepted August 5, 2019.
$\mathrm{T}$ ension-type headache (TTH) is estimated to affect 65.6 million people in the United States, exceeding the number of those affected by migraine. ${ }^{1}$ It is categorized as episodic, frequent episodic, or chronic, with significant disability and resistance to medical management associated with the latter types. ${ }^{2}$ The pain associated with TTH is commonly bilateral and is often described as a dull, band-like sensation around the frontal, temporal, and suboccipital regions of the head; the neck may also be affected. Tension-type headache is most commonly triggered by mental stress and muscle tension, which suggests a mind-body-spirit connection that may be optimally treated with an osteopathic approach. $^{3}$

Superficially, the posterior neck is covered in deep cervical fascia. This fascia attaches at the midline to the external occipital protuberance, nuchal ligament, and the seventh cervical spinous process. It then spreads laterally to envelop the trapezius muscle before attaching to the scapula. ${ }^{4}$ The deep muscles of the posterior neck include the splenius, iliocostalis, longissimus, semispinalis, and multifidus. As a group, these muscles are extensors and rotators of the head and cervical spine, and they may become hypertonic and overactive in chronic forward-head positions. ${ }^{5}$ The suboccipital muscle group comprises the rectus capitis major and minor and the obliquus capitis superior and inferior, attaching to the occiput, atlas, and axis, and it may play a role in headache by exerting tension on the dura mater through myodural bridges. ${ }^{6-8}$

Innervation to the posterior head and neck is provided by the cervical spinal nerves, with a large area of the posterior head receiving its sensory innervation from the greater occipital nerve (dorsal ramus of C2), third occipital nerve (dorsal ramus of $\mathrm{C} 3$ ), and the lesser occipital and great auricular nerve (ventral ramus of $\mathrm{C} 2$ ). ${ }^{4}$ The trapezius and semispinalis capitis muscles are pierced by the greater occipital nerve as it courses superiorly to transmit sensory innervation from the posterior scalp. ${ }^{9}$ It is postulated that compression of the greater occipital nerve, facilitated by the hypertonic trapezius and semispinalis capitis, causes referred pain to the dura mater by a convergence of afferents from the trigeminal nerve and the greater occipital nerve in the dorsal horn of C2. ${ }^{10}$ Sensory innervation to the face occurs primarily via the 3 divisions (ophthalmic, maxillary, and mandibular) of the trigeminal nerve. ${ }^{4}$

Although the pathogenesis of TTH is not well understood, current theories implicate cervical myofascial trigger points, forward head posture, restrictions in cervical mobility, and referred pain. ${ }^{11-13}$ Somatic dysfunction of the muscles of the neck or suboccipital region may contribute to headache via tissue texture changes, restriction of motion, referred pain, and tenderness. A review of the literature shows improvement in pain, frequency, and headache disability index scores with manual therapy and osteopathic manipulative treatment (OMT). ${ }^{14-17}$ One randomized placebocontrolled trial showed significant improvements in the frequent episodic subtype of TTH after OMT. ${ }^{18}$ In another study, soft tissue and articulatory techniques were shown to reduce depression and anxiety and improve headache in patients with TTH, highlighting the interrelatedness of mind and body in this condition. ${ }^{19}$

Two OMT techniques that may be safe and effective in the prevention and management of TTH are bilateral cervical stretch and contralateral traction, as demonstrated in the video.

Contraindications to these soft-tissue OMT techniques in the cervical region include open wounds, acute cervical fractures, cutaneous infections, local malignancy, and serious vascular 
compromise. In addition, direct stretching of acutely injured muscles, tendons, ligaments, or joint capsules may cause additional tissue damage or increase pain and should therefore be avoided. ${ }^{20}$

Tension-type headache is associated with biomechanical, psychological, and behavioral triggers and forms the basis for a multimodal treatment approach. ${ }^{20}$ Osteopathic manipulative treatment may be a useful adjuvant treatment to assist in alleviating musculoskeletal elements contributing to TTH. The techniques demonstrated in this video are not intended to treat any specific clinical condition but are only one aspect of the diagnosis and treatment plan that an osteopathic physician would use to address the whole patient. (doi:10.7556/jaoa.2019.096)

\section{Acknowledgments}

We thank Jeff Reedy for video contributions and Dennis Chou, OMS II, for serving as the patient in the video.

\section{References}

1. GBD 2016 Headache Collaborators. Global, regional, and national burden of migraine and tension-type headache, 1990-2016: a systematic analysis for the Global Burden of Disease Study 2016. Lancet Neurol. 2018;17(11):954-976.

2. Steiner TJ, Martelleti $P$; Aids for management of common headache disorders in primary care. J Headache Pain. 2007;8(suppl 1):428. doi:10.1007/s10194-007-0428-1

3. Rasmussen BK. Migraine and tension-type headache in a general population: precipitating factors, female hormones, sleep pattern and relation to lifestyle. Pain. 1993;53(1):65-72.

4. Standring S. Gray's Anatomy: The Anatomical Basis of Clinical Practice. 41st ed. Elsevier; 2016:493-495.

5. Florencio LL, Ferracni GN, Chaves TC, et al. Analysis of head posture and activation of the cervical neck extensors during a low-load task in women with chronic migraine and healthy participants. J Manipulative Physiol Ther. 2018;41(9):762-770. doi:10.1016 jj.jmpt.2018.07.002

6. Palomeque-del-Cerro L, Arráez-Aybar LA, Rodriguez-Blanco C, Guzmán-García R, Menendez-Aparicio M, Oliva-Pascual-Vaca Á. A systematic review of the soft-tissue connections between neck muscles and dura mater: the myodural bridge. Spine. 2017;42 (1):49-54.
7. Enix DE, Scali F, Pontell ME. The cervical myodural bridge, a review of literature and clinical implications. J Can Chiropr Assoc. 2014;58 (2):184-192.

8. Luedtke K. Does the rectus capitis posterior minor muscle contribute to the pathogenesis of chronic headache? Cephalalgia. 2017;37 (11):1015-1016.

9. Drake R, Vogl AW, Mitchell AW. Gray's Anatomy for Students. 3rd ed. Philadelphia, PA: Churchill Livingstone; 2015:925.

10. Goadsby P. Migraine, allodynia, sensitisation and all of that.... Eur Neurol. 2005;53(suppl 1):10-16. doi:10.1159/000085060

11. Fernández-de-las-Peñas $C$, Alonso-Blanco $C$, Cuadrado $M$, Pareja JA Forward head posture and neck mobility in chronic tension-type headache: a blinded, controlled study. Cephalalgia. 2006;26 (3):314-319. doi:10.1111/j.1468-2982.2005.01042.x

12. Chatchawan U, Thongbuang S, Yamauchi J. Characteristics and distributions of myofascial trigger points in individuals with chronic tension-type headaches. J Phys Ther Sci. 2019;31(4):306-309. doi:10.1589/jpts.31.306

13. Castien R, De Hertogh W. A neuroscience perspective of physical treatment of headache and neck pain. Front Neurol. 2019;10:276. doi:10.3389/fneur.2019.00276

14. Seffinger MA, Halbeison A. Headaches are a pain in the neck [abstract of Espí-López GV, Rodríguez-Blanco C, Oliva-Pascual-Vaca A, Benítez-Martínez JC, Lluch-Girbés E, Falla D. The effect of manual therapy techniques on headache disability in patients with tension-type headache [published online April 30, 2014]. Eur J of Phys Rehabil Med]. J Am Osteopath Assoc. 2014;114(7):590-591. doi:10.7556 ljaoa.2014.118

15. Jiang W, Li Z, Wei N, Chang W, Chen W, Sui HJ. Effectiveness of physical therapy on the suboccipital area of patients with tension-type headache: a meta-analysis of randomized controlled trials. Medicine (Baltimore). 2019;98(19):e15487. doi:10.1097/MD.0000000000015487

16. Gallagher RM. Headache pain. J Am Osteopath Assoc. 2005;105 (9 suppl 4):S7-S11.

17. Moraska A, Chandler C. Changes in clinical parameters in patients with tension-type headache following massage therapy: a pilot study. J Man Manip Ther. 2008;16(2):106-112.

18. Rolle G, Tremolizzo L, Somalvico F, Ferrarese C, Bressan LC. Pilot trial of osteopathic manipulative therapy for patients with frequent episodic tension-type headache. J Am Osteopath Assoc. 2014;114 (9):678-685. doi:10.7556/jaoa.2014.136

19. Essí-López GV, López-Bueno L, Vicente-Herrero MT, Martinez-Arnau FM, Monzani L. Efficacy of manual therapy on anxiety and depression in patients with tension-type headache: a randomized controlled clinical trial. Int J Osteopath Med. 2016;22:11-22. doi:10.1016 /j.josm.2016.05.003

20. Bendtsen L, Evers S, Linde M, Mitsikostas DD, Sandrini G, Schoenen $\mathrm{J}$; EFNS. EFNS guideline on the treatment of tension-type headache report of an EFNS task force. Eur J Neurol. 2010;17(11):1318-1325.

๑) 2019 American Osteopathic Association 